\title{
Conferência
}

\section{A língua no desenvolvimento humano: a escola e a criança'}

\author{
Mary Elizabeth Cerutti-Rizatti2
}

A língua é constitutiva do desenvolvimento humano porque é constitutiva das relações de convivência nas quais nos apropriamos dos produtos culturais historiados. Nós nos tornamos 'humanos' nessa apropriação da cultura e não há como fazer isso senão por meio da língua; inicialmente pela modalidade oral e, depois, adicionalmente, também pela modalidade escrita. E a escola é a instituição criada pela cultura para promover o desenvolvimento humano desde a infância até a idade adulta. Logo, a escola é lugar não só da língua, mas de pensar sobre a língua.

E, se a escola foi criada para desenvolver o homem, ela não pode, em suas ações e processos, mimetizar-se com o cotidiano linguístico em que o sujeito está imerso. É papel escolar desafiar esse sujeito, em todo o seu percurso formativo, a inquietar-se com o modo como ele e os outros usam a língua, o que exige atenção para a forma como a realidade natural e social é nomeada, no dia a dia e para além dele, e quais são as relações de sentido ali estabelecidas, desde as mais rotineiras relações familiares (linguagem afetiva ou xingamentos em casa, por exemplo), até as questões mais complexas de organização universal (a língua na 'arte' ou a língua no 'preconceito', por exemplo). E isso exige pensar sobre a língua, porque requer apropriação de referenciais que extrapolam nosso entorno imediato, de modo a operarmos com significados e sentidos necessariamente representados pela/na língua. Afinal, só podemos problematizar o que nos cerca quando nos habilitamos a avaliar nosso cotidiano a partir de

\footnotetext{
1 Palestra realizada em 20 de agosto de 2020 aos alunos na Disciplina Fundamentos Teóricopráticos de Língua Portuguesa, curso de Pedagogia da Ufopa.

2 Doutora em Letras. Líder do Grupo de Pesquisa "Cultura Escrita e escolarização" (UFSC).

ORCID id: https://orcid.org/0000-0002-6635-4245. E-mail: ma.rizzatti@gmail.com
} 
referenciais externos a ele, porque o desenvolvimento humano exige tensionamento entre o cotidiano, de um lado, e a abstração científica e filosófica de outro. E, em tudo isso, a língua é fundamental.

\section{A língua na educação infantil}

Entendo que o educador infantil acompanha o processo de aquisição da língua, portanto, convive com a historicidade inicial dos sujeitos na apropriação da modalidade oral de sua língua materna: a criança, na Educação Infantil, está 'aprendendo a falar'. Aqui, a ação docente é fundamental porque lida com o embrião da nomeação do mundo por parte da criança, tanto quanto com as primeiras relações linguísticas que ela estabelece entre si mesma e os objetos de mundo (como se coloca diante de um brinquedo que quer ou não para si, por exemplo), e dos objetos de mundo entre eles mesmos (como representa linguisticamente 'uma bola rolar e bater em outra a deslocando', por exemplo). A língua constitui cada uma dessas vivências das quais resulta o desenvolvimento infantil.

Vivências como essas, porém, caracterizam o cotidiano das crianças em espaços domésticos, familiares e afins, desde 'aprender' como nomear o cuidador mais próximo, geralmente a mãe, até como transcender do choro para a nomeação da fome, do frio, do desconforto: de grunhidos e balbucios, a criança passa ao uso de palavras, desde as holofrases (como 'ág[u]a' para 'quero água') até sentenças maiores e mais complexas. Isso ocorre, pela via da língua, na escola e fora da escola, mas deve haver profundas diferenças entre um e outro desses dois espaços sociais.

\subsection{Distinções entre a intervenção escolar na Educação Infantil e os demais espaços culturais em se tratando da língua}

O papel do educador infantil quanto ao desenvolvimento linguístico da criança precisa atender a uma orientação muito bem definida: compreender que tem diante de si sujeitos em processo de aquisição da 
modalidade oral da língua e que não the cabe 'ficar assistindo' a essa aquisição e (como os familiares), alegrando-se com progressos dela. $O$ educador infantil, ao contrário do espontaneísmo familiar, precisa planejar atividades para o enriquecimento desse processo aquisicional, criando situações educacionais desafiadoras, em que as crianças possam ir além do que conseguiriam ir em suas vivências cotidianas domésticas. O educador infantil precisa interferir nesse processo de aquisição da linguagem para qualificá-lo maximamente.

\subsection{Importância dessa intervenção desde a aquisição da linguagem}

A língua se presta para se nomear a realidade natural e social e predicar-se sobre ela: quando usamos a língua trazemos uma parte do mundo para a nossa 'conversa' ('o clima', por exemplo) e predicamos sobre essa parte ('[o clima] está mudando muito'). E isso vai além da estrutura das línguas (haver frases formadas por nomes e verbos, por exemplo) porque depende intrinsecamente de como a cultura humana lida com a realidade. Crianças na Educação Infantil tendem, por exemplo, a referenciar o mundo por hiperônimos: tudo o que tiver quatro patas, rabo e focinho costuma ser nomeado como 'au-au'. A distinção categorial de 'au-au' para 'miau', até chegar à identificação de 'coelhos' e outros mamíferos quadrúpedes, ou até mesmo chegar à distinção de raças específicas de cães, exige um percurso educacional em que haja interlocutores que desafiem a criança a pensar. E, na escola, esse desafio é diferente das situações espontâneas familiares: na escola o desafio tem de ser intencional e planejado.

É comum vermos, por exemplo, crianças que estão imersas em famílias de maior escolaridade (e também de maior poder aquisitivo) que valorizam os processos educacionais usarem precocemente termos bem específicos em lugar de genéricos - como nomear raças de cães ("Este 'poodle' [e não este (cachorro'] é meu, moça!"), enquanto outras crianças, inseridas em ambientações em que a escolaridade não é questão relevante (o que tem profundas relações com condições socioeconômicas), usarem nomes 
genéricos quando já poderiam usar nomes mais específicos (indistinguem, por exemplo, 'rosas' e 'margaridas', conseguindo nomeá-las apenas como 'flores').

Chegar aos hipônimos - nomes mais específicos -, para manter o mesmo exemplo, não constitui apenas, como tendem a pensar linguistas formais, mera 'aquisição de vocabulário' (ou léxico), ou de 'morfologia', distinções categorias em si e por si mesmas. Trata-se da apropriação de formas mais complexas ou menos complexas de como a cultura organiza a realidade natural e social; trata-se, então, da apropriação de conceitos, e conceitos ligam-se ao pensamento abstrato. Quando as crianças usam um termo com adequação, fazem-no porque se apropriaram dos conceitos respectivos a ele: quando se apropriam do conceito 'margarida', conseguem lidar com a palavra 'margarida' em todas as situações em que houver uma flor desse tipo, não se restringindo a uma 'margarida' em particular, aquela que a mãe eventualmente tenha nas mãos. Isso pode começar pela imitação da linguagem dos adultos: ver a mãe nomeando como 'margarida' a flor que tem nas próprias mãos. Logo, em havendo, no entorno, adultos a 'imitar', esse começo é possível; em não havendo, tornase mais custoso. De todo modo, uma palavra só entra no repertório da criança se ela vivenciar - bem além da imitação - o conceito correspondente a essa palavra, e só se apropria dele quando o abstrair: aprendeu o que são 'margaridas' e será capaz de reconhecer uma delas, não mais a chamando apenas genericamente de 'flor'. É papel da escola promover esse processo de ampliação conceitual na vida das crianças.

E ainda: apropriar-se da forma como a cultura organiza o mundo significa apropriar-se também das valorações sociais e culturais atribuídas a essa mesma realidade natural e social. Assim, por exemplo, educar a criança para afastar-se de 'aranhas' e aproximar-se de 'borboletas', exige que ela, mais do que adquirir esses substantivos - 'aranha' e 'borboleta' - em seu percurso de desenvolvimento linguístico, aproprie-se também dos conceitos a eles respectivos (uma 'aranha' é peçonhenta; e uma 'borboleta', não; e afins), assim como de valores que a cultura imprime a essas palavras. E esses 
valores são constitutivos dos discursos. Logo, quando uma criança agride outra com a palavra 'bobo', por exemplo, pode estar imitando um comportamento que presenciou, mas a imitação é sempre início de processo de apropriação do conceito correspondente à palavra usada. E aí entra a intervenção escolar: criar condições para que as crianças problematizem os usos que fazem - e/ou que presenciam - da língua, quer para a expansão cognitiva desses usos (mover-se do hiperônimo 'flor' ao hipônimo 'margarida'), quer para a monitoria discursiva deles (quando 'bobo' soa como brincadeira fraterna, e quando 'bobo' constitui ofensa).

\section{3 ‘Que'de língua ensinar na Educação Infantil...}

Tendo presente que o período de desenvolvimento humano correspondente à Educação Infantil tem 'o brincar' como principal forma de a criança operar com o mundo, o educador infantil precisa organizar esse brincar, de modo intencional e sistemático, em favor do desenvolvimento linguístico da criança, o que significa compreender a aquisição da fala como apropriação das formas de organização da cultura humana. Para isso, é preciso criar atividades lúdicas nas quais novas palavras sejam gradualmente inseridas, vivenciadas na sua dimensão conceitual: a criança adquire a palavra 'árvore' e, aos poucos, pela via dos jogos pedagógicos, adquire também 'palmeira' e, para manter o exemplo, 'jerivá', em uma relação conceitual cada vez mais refinada e complexa, de modo que, ao defrontar-se com esses elementos do meio ambiente, possa autodominar sua conduta linguística nessa nomeação, porque abstraiu os conceitos correspondentes aos termos. Esse é apenas um exemplo; o mesmo vale para como a língua indicia numerais: se for mais de uma unidade, serão 'árvores', 'palmeiras', jerivás'; ou gênero gramatical: 'as' para 'árvores' e 'palmeiras', mas 'os' para 'jerivás', com implicações de concordância e afins, sobretudo naquelas ambientações em que a variação diastrática não prevê formas de oralidade mais próximas da modalidade escrita. 
Pensar sobre essas representações cognitivas e sobre essas relações gramaticais, pela via planejada e sistemática do brincar - cantigas, jogos, contos e congêneres -, é caminho para que a criança se eduque de modo a prestar atenção, desde o processo aquisicional, a como a cultura organiza a realidade natural e social por meio da língua. Logo, não se trata de ensinar ludicamente conhecimentos meramente formais sobre a estrutura da língua ou tão somente 'novas palavras'; trata-se de introduzir paulatinamente a crianças nos modos mais complexos como a cultura humana se organiza para lidar com o mundo físico e social, sobretudo naqueles espaços socioeconômicos em que não há outros agentes - além da escola - para fazer isso. Assim, maior repertório linguístico implica maior repertório conceitual e, portanto, maior apropriação cultural. E isso depende em boa medida de como o educador infantil interfere pedagogicamente no processo de aquisição da linguagem. Em síntese: importa desde o processo aquisicional ensinar a criança a pensar sobre a língua, a partir de uma ação pedagógica lúdica em que esse pensar sobre a língua corresponda a pensar sobre a organização da cultura humana, em crescente 'automonitoramento' e 'heterocriticidade' desde os primeiros anos da vida, respeitadas as possibilidades de desenvolvimento de cada fase da infância.

\section{A língua nos anos iniciais: aproximações e distinções em relação à educação infantil}

O percurso de aquisição de linguagem mantém-se nos Anos Iniciais, porque o processo de apropriação conceitual ligado à ampliação do vocabulário é contínuo e há formas linguísticas que são de aquisição mais tardia, como o domínio da narrativa, da voz passiva entre outras. Assim, muito do que foi dito sobre o papel do educador infantil mantém-se para os Anos Iniciais. Há, porém, agora, um importante elemento novo: o 'aprendizado da modalidade escrita da língua'. Assim, a imersão da criança nas formas mais complexas de organização da cultura, antes relativas à modalidade oral, agora ganham o adicional da modalidade escrita da 
língua. E isso abre um universo infinitamente amplo de novas possibilidades de conhecer a realidade natural e social e lidar com ela. O educador dos Anos Iniciais, então, tem consigo a responsabilidade de imergir maximamente o sujeito na cultura escrita, nas relações, mais estreitas (caso da alfabetização) ou menos estreitas (como na literatura 'clássica') que essa cultura estabelece com a oralidade.

\section{1 'Que' de língua ensinar além do 'já sabido' acerca da alfabetização...}

É certo que alfabetizar as crianças é condição para a imersão na cultura escrita. E fazer isso exige que elas dominem as relações grafêmicofonêmicas (leitura) e fonêmico-grafêmicas (escritura) em um processo gradual que precisa estar concluído nos três primeiros anos do Ensino Fundamental, à exceção daquelas relações chamadas 'arbitrárias' que envolvem a ortografia da língua e cujo aprendizado estende-se ao longo da Educação Básica, sendo acelerado ou retardado a depender do ritmo e da intensidade do processo de formação dos estudantes como leitores (dominar as diferentes representações grafêmicas do fonema /s/, por exemplo, requer amplas vivências de leituras). Esse processo é favorecido quando se realizam atividades de consciência fonológica, como jogos de rimas e afins, nas quais as crianças conseguem pensar sobre a organização do contínuo da fala, o que, sem a alfabetização, tende a não ocorrer, pelo menos não nos segmentos mínimos como a relação grafema/fonema.

Isso, no entanto, nos parece amplamente discutido sob o tema 'alfabetização'. Então, para além desse tema, 'que' de língua ensinar nestes Anos? Alfabetizar-se é instrumental para a textualização na leitura e na escritura, questão fundante da cultura escrita. E textualizar via escrita, na compreensão e na produção, exige, mas transcende, dominar o sistema de escrita alfabética e suas particularidades ortográficas, porque envolve intrincadas operações cognitivas, do que são exemplos 'narrar / expor / argumentar / descrever / explicar / interpretar', com implicações como relações entre 'causa/consequência', 'instrumento / finalidade', 'espaço / 
tempo', 'dado / novo', 'afirmação/interrogação/exclamação' e tantos outros comportamentos linguísticos sem os quais a textualização não ocorre. Assim, entendo que aqui está ponto importante em se tratando de 'que' de língua ensinar nestes Anos Iniciais: indicadores linguísticos que qualifiquem os modos de as crianças operarem cognitivamente na textualização [sobretudo a] escrita, condição para apropriação das manifestações mais complexas da cultura humana.

As relações espaço-temporais e causais-consecutivas, por exemplo, são condição para leitura proficiente de contos clássicos, narrativas, fundamentais nestes Anos Iniciais, porque figurativizam importantes relações familiares, afetivas, de espiritualidade, de poder, políticas, econômicas e tantas outras. E nessa figurativização, as crianças vivenciam modos de organização social característicos da produção cultural humana. Sob o ponto de vista linguístico, qualificar-se como leitor - destes contos e de textos em outros tantos gêneros - exige monitorar o tecido textual na organização dos espaços, do tempo, da linearidade causal-consecutiva dos fatos narrados e afins, para o que concorrem os tempos verbais, os conectivos, os marcadores temporais e congêneres. E qualificar-se como leitor tem, como contraface, qualificar-se também como escritor, condições para autodomínio na imersão na cultura escrita.

Também aqui a base do argumento é a dimensão conceitual da apropriação cultural. Lidar com o 'tempo', por exemplo, exige monitorar linguisticamente indicativos de presente, passado e futuro, para $\circ$ que a alternância dos tempos e modos verbais é decisiva. As personagens são descritas no pretérito imperfeito, e suas ações são historiadas no pretérito perfeito, por exemplo. Os Anos Iniciais não são lócus para abordagens sistêmicas como identificar, classificar ou flexionar tempos e modos verbais, mas seguramente o são para identificar os movimentos temporais que a cultura humana historiou, e isso implica monitorar os verbos, a fim de que 0 ato de narrar torne possivel o presente conhecer o passado, e o futuro conhecer o presente. Trata-se, enfim, de uma ação pedagógica que organize as atividades de leitura e de escritura em atenção aos recursos de 
que a língua dispõe para que as narrativas (neste exemplo) se textualizem, e isso vai desde (i) nomes selecionados para referenciação do real, pronomes em correferenciação e qualificativos para esses nomes; passando por (ii) alternância de tempos e modos verbais para historiar os fatos e descrever personagens e espaços; até (iii) articuladores da marcação/passagem de tempos e espaços e elementos afins.

Detenho-me na narrativa - que constitui diferentes gêneros do discurso - porque a compreendo fundante do desenvolvimento infantil nos Anos Iniciais; os poemas poderiam ser discutidos também aqui, pela dimensão de arte lúdica que os constitui. De todo modo, a questão me parece ser, em síntese: organizar atividades de leitura e escritura pedagogicamente dirigidas de modo que os sentidos produzidos estejam linguisticamente indiciados/ancorados; em outras palavras, que o educador, nestes Anos, fundamente na identificação de características linguísticas do texto as tarefas que propõe às crianças, de modo à paulatinamente trazer à consciência discente como a língua indicia os sentidos mapeados. Fazer isso de modo recorrente e planejado faculta a gradual abstração conceitual: quando eu (ou o autor que leio) usa verbos 'tais', ele indica que um fato aconteceu antes de outro fato já concluído (no caso do mais-que-perfeito), por exemplo. Isso feito, nos Anos Finais do Ensino Fundamental, o domínio conceitual explícito do verbo será facilitado.

Enfim, a língua, na Educação Básica, é objeto de ensino e de aprendizagem (e não objeto de estudo e de pesquisa, como é na Educação Superior); logo, precisa ser ensinada e aprendida (não se concebendo as escolas como equivocados territórios de pesquisa sobre a língua). Seguramente não se trata de ensinar o que o sujeito já sabe, porque é sua língua materna; trata-se de ensinar a ele com monitorar os usos que faz dessa língua, que é sua, nas relações de convivência humana; para isso, é necessário que se aproprie dos modos como a cultura humana historiou a língua nessas mesmas relações, e isso a escola deve the ensinar. 


\section{Alguns fundamentos referenciais}

CHOMSKY, Noam. Linguagem e mente. São Paulo: Unesp, 2009.

DUARTE, Newton. A individualidade para si: contribuição a uma teoria histórico-crítica da formação do indivíduo. Campinas, SP: Autores Associados, 2013.

PIAGET, Jean. Epistemologia genética. São Paulo: Martins Fontes, 2007.

PINKER, Steven. $O$ instinto da linguagem: como a mente cria a linguagem. São Paulo: Martins Fontes, 2002.

SCLIAR-CABRAL, Leonor. Guia prático de alfabetização. São Paulo: Contexto, 2003.

VIGOTSKI, Lev. Pensamiento y habla. Buenos Aires: Colihue, 2012 [1934].

VYGOTSKI, L. S. El instrumento y el signo em el desarrollo del niño. In: VYGOTSKI, L.S. Herencia científica. Obras Escogidas, Tomo VI. Madri: Machado Libros, 2017 [1930], p. 9-100.

VOLOCHÍNOV, Valentin N. Que é a linguagem? In: VOLOCHÍNOV, Valentin N. A construção da enunciação e outros ensaios. São Carlos/SP: Pedroo \& João, 2013 [1930], p. 131-156.

Recebido em: 21 de agosto de 2020 Aprovado em: 04 de setembro de 2020 Publicado em: 09 de setembro de 2020 